\title{
Non-Linear Analysis of the Fisher Effect: In the Case of Japan
}

\author{
Katsuhiro Sugita ${ }^{1}$ \\ ${ }^{1}$ Faculty of Law and Letters, University of the Ryukyus, Japan \\ Correspondence: Katsuhiro Sugita, Faculty of Law and Letters, University of the Ryukyus, Senbaru 1, Nishihara, \\ Nakagami, Okinawa 903-0213, Japan. E-mail: ksugita@11.u-ryukyu.ac.jp
}

Received: August 14, 2017

Accepted: August 30, 2017

Online Published: September 25, 2017

doi:10.5539/ijef.v9n11p1

URL: https://doi.org/10.5539/ijef.v9n11p1

\begin{abstract}
The Fisher effect has been commonly analyzed to investigate the long-run relationship between nominal interest rates and expected inflation rate, though it is rarely successful in finding the cointegration relationship as the Fisher effect states. In this paper, a Bayesian Markov switching vector error correction model is applied to analyze non-linearity in the Fisher effect in the case of Japan. We find that the Fisher effect holds in one regime although it does not hold in another regime when the nominal interest rate is stable and does not respond against disequilibrium by the monetary policy such as the zero interest rate policy. This model reveals non-linearity in the error correction mechanism of the Fisher effect in Japan.
\end{abstract}

Keywords: Bayesian, cointegration, Markov-switching, Fisher effect

\section{Introduction}

The Fisher equation states that nominal interest rates are related with expected inflation rate in the long-run. Many researchers have empirically investigated the cointegrated relationships. However, empirical researches are rarely successful to find the long-run cointegration relationship between the two variables. Engsted (1995), Atkins and Serletis (2003), Rapach (2003), and Rapach and Weber (2004), among others, analyze the cointegration for the Fisher effect and conclude that there is no evidence for the Fisher effect. On the other hand, Bierens (2000), Kapetanios et al. (2003), and Lanne (2006) consider nonlinear models for cointegration and find that failure of the Fisher effect is due to the non-linearity. Gregory et al. (1996) and Beyer et al. (2009) study cointegration for the Fisher effect using models with structural breaks and find that the structural breaks influence the long-run relation between the two variables. Christopoulos and León-Ledesma (2007) find that the empirical failure of the Fisher effect may be due to the existence of non-linearities in the cointegrating vector, caused by monetary policy.

In this paper, we apply a Bayesian Markov switching vector error correction model (MSVECM) to investigate the Fisher effect in Japan. A Bayesian MSVECM, based on Jochmann and Koop (2015), allows the regime shift in any parameter in the vector error correction model such as the cointegration rank, the cointegrating vector, and the lag length as well as other parameters in the model, so that we can study whether the non-linearities by monetary policy influence the error correction mechanism and the dynamic mechanism.

The remainder of the paper is organized as follows. Section 2 overviews the Fisher effect and Japanese monetary policy. An MSVECM is introduced in Section 3. We specify the prior densities and show the conditional posterior densities. Section 4 presents the econometric results. Section 5 concludes. We use Ox v7.03 (Doornik (2013)) to write code for computation for this paper.

\section{Fisher Effect and Japanese Monetary Policy: Overview}

In this section, we offer a very brief overview of the Fisher effect and Japan's monetary policy. The Fisher effect states that the nominal interest rate is determined by the real interest rate and the expected inflation rate as $R_{t}=r_{t}$ $+E_{t}\left[\pi_{t}^{s}\right]$ where $R_{t}$ is the nominal interest rate that matures in period $t+s ; r_{t}$ is the real interest rate; $E\left[\pi_{t}^{s}\right]$ is the expected inflation rate in period $t+s$. Assuming rational expectation, $E_{t}\left[\pi_{t}^{s}\right]=\pi_{t}^{s}+\varepsilon_{t}, \varepsilon_{t} \sim i i d N\left(0, \sigma^{2}\right)$, we have $R_{t}=$ $r_{t}+\pi_{t}^{s}+\varepsilon_{t}$, that implies the monetary super-neutrality. If both $R_{t}$ and are $I(1)$, both rates should be cointegrated and its cointegrating vector is $(1,-1)$. 

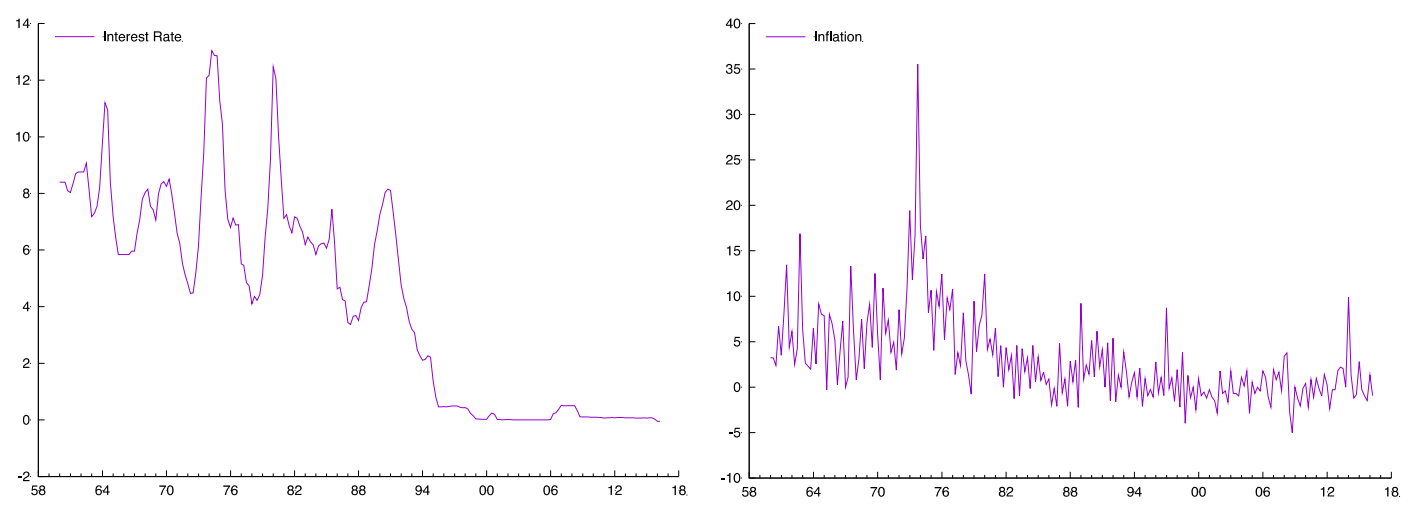

Figure 1. Money market rate (left) and CPI inflation (right)

In this paper we examine whether the nominal interest rate and the inflation rate of Japan are related as the Fisher effect states using nonlinear regime switching cointegration model. Figure 1 depicts Japanese money market rate as nominal interest rate and the CPI inflation rate from 1960 to 2016. The nominal interest rate has fluctuated except for the period between 1964 and 1965 and the period since the late 1990s. In the period between 1964 and 1965, Japan experienced the securities market slumps and the Bank of Japan (BOJ) reduced the official discount rate. In the late 1980, Japan experienced the bubbled economy until the early 1990s. Then, the Japanese economy slowed down considerably after the bubble burst in 1992. The interest rate has dropped accordingly since then. The BOJ lowered the official discount rate suddenly in 1995, and adopted the zero interest rate policy (ZIRP) since 1999 - the uncollateralized overnight call rate (the targeted policy rate) was lowered to nearly zero per cent. The ZIRP was abandoned in 2000, however, it was adopted again with the quantitive easing (QE) policy (Note 1) in 2001. The BOJ ceased these policies in 2006, however, these policies were adopted again in 2008 along with the Lehman shock in US, and the interest rates have been barely fluctuated around zero per cent since then.

As Christopoulos and León-Ledesma (2007) suggest, monetary policy such as the ZIRP may influence the relationship between nominal interest rates and inflation in Japan, and thus nonlinearity may exist in the equilibrium relationship between the two variables.

\section{Markov Switching Cointegration Model}

This section introduces a Bayesian approach to a Markov switching cointegration model based on Jochmann and Koop (2015). Cheung and Lai (1993) show that the Johansen's cointegration tests are sensitive to the choice of the lag length. Bayesian cointegration analysis would also be affected by the choice of the lag length, so that we arrange the original model by Jochmann and Koop (2015), that suppose the lag length is constant over all regimes, to allow the regime shifts in the lag length.

Let $y_{t}$ denote $1 \times n$ vector of $I(1)$ with $r$ cointegrating vector. A VAR $(p)$ model with $\varepsilon_{t} \sim \operatorname{iidN}(0, \Omega)$ can be written as a vector error correction model (VECM) as:

$$
\Delta y_{t}=\left(y_{t-1} \beta+\mu_{1}+t \delta_{1}\right) \alpha+\mu_{2}+t \delta_{2}+\sum_{l=1}^{p-1} \Delta y_{t-l} \Gamma_{l}+\varepsilon_{t}
$$

where $\beta(n \times r)$ is the cointegrating vector; $\mu_{1}(1 \times r)$ is the deterministic constant term and $\delta_{1}(1 \times r)$ is the deterministic time trend term in the cointegration relations; $\alpha(r \times n)$ is the adjustment term; $\mu_{2}(1 \times n)$ is the deterministic constant term and $\delta_{2}(1 \times n)$ is the deterministic time trend term in the $\mathrm{VECM} ; \Gamma_{l}(n \times n)$ is the lag term.

We consider a Markov switching vector error correction model (MSVECM) where the cointegrating vector $\beta$, the number of the cointegrating rank $r$, the adjustment terms $\alpha$, the deterministic term $\mu$, the lag length $p-1$, the lag term $\Gamma$, and the variance-covariance matrix $\Omega$ are subject to the regime $i=0,1, \ldots, m-1$ such as:

$$
\Delta y_{t}=\left(y_{t-1} \beta(i)+\mu_{1}(i)+t \delta_{1}(i)\right) \alpha(i)+\mu_{2}(i)+t \delta_{2}(i)+\sum_{l=1}^{p(i)-1} \Delta y_{t-l} \Gamma_{l}(i)+\varepsilon_{t}
$$

where $\varepsilon_{t}(i) \sim N(0, \Omega(i))$. The MSVECM in (2) differs from the model used by Jochmann and Koop (2015) or Sugita (2016): the model in (2) allows the lag length to change with regime.

Let $Y=\left(\Delta y_{1}^{\prime}, \ldots, \Delta y_{T}^{\prime}\right)^{\prime}$, then the MSVECM in (2) can be written as a matrix format in the following way:

$$
Y=\sum_{i=0}^{m-1}\left\{Z(i) \beta^{*}(i) \alpha(i)+X(i) \Phi(i)\right\}+E
$$


where

$$
\begin{aligned}
& \beta^{*}(i)=\left(\beta^{\prime}(i), \mu_{1}(i)^{\prime}, \delta_{1}(i)^{\prime}\right)^{\prime}, E=\left(\varepsilon_{1}^{\prime}, \ldots, \varepsilon_{T}^{\prime}\right)^{\prime}, \\
& \Phi(i)=\left(\mu_{2}(i), \delta_{2}(i), \Gamma_{1}(i), \ldots, \Gamma_{p(i)-1}(i)\right), \\
& Z(i)=\left[\begin{array}{ccc}
\iota_{1}(i) y_{0} & \iota_{1}(i) & \iota_{1}(i) \\
\iota_{2}(i) y_{1} & \iota_{2}(i) & 2 \iota_{2}(i) \\
\vdots & \vdots & \vdots \\
\iota_{T}(i) y_{T-1} & \iota_{T}(i) & T \iota_{T}(i)
\end{array}\right], \\
& X(i)=\left[\begin{array}{cccccc}
\iota_{1}(i) & \iota_{1}(i) & \iota_{1}(i) \Delta y_{0} & \iota_{1}(i) \Delta y_{-1} & \cdots & \iota_{1}(i) \Delta y_{-p(i)} \\
\iota_{2}(i) & 2 \iota_{2}(i) & \iota_{2}(i) \Delta y_{1} & \iota_{2}(i) \Delta y_{0} & \cdots & \iota_{2}(i) \Delta y_{-p(i)+1} \\
\vdots & \vdots & \vdots & \vdots & \ddots & \vdots \\
\iota_{T}(i) & T \iota_{T}(i) & \iota_{T}(i) \Delta y_{T-1} & \iota_{T}(i) \Delta y_{T-2} & \cdots & \iota_{T}(i) \Delta y_{T-p(i)-1}
\end{array}\right],
\end{aligned}
$$

and $l_{t}(i)$ is the indicator variable that equals to 1 if regime is $i$ at $t$, and 0 otherwise.

Koop et al. (2010) develop an efficient posterior simulation method using a collapsed Gibbs sampler, and Jochmann and Koop (2015) and Sugita (2016) apply the method for a Markov switching cointegration model. Koop et al. (2010) propose the following priors:

$$
\beta \alpha=(\beta \kappa)\left(\kappa^{-1} \alpha\right)=\left[\beta\left(\alpha \alpha^{\prime}\right)^{1 / 2}\right]\left[\left(\alpha \alpha^{\prime}\right)^{-1 / 2} \alpha\right] \equiv b a
$$

where $\kappa \equiv\left(\alpha \alpha^{\prime}\right)^{1 / 2}$ is a positive definite. Thus, the MSVECM in (3) can be written as:

$$
Y=\sum_{i=0}^{m-1}\left\{Z(i) b^{*}(i) a(i)+X(i) \Phi(i)\right\}+E
$$

To estimate the MSVECM in (4), we need to assign prior densities for all parameters. We assign the following priors for parameters in (4):

$$
\begin{gathered}
\operatorname{vec}\left(b^{*}(i)\right) \sim N\left(\operatorname{vec}\left(b_{0}^{*}(i)\right), V_{b_{0}}(i)\right) \\
\operatorname{vec}(a(i)) \sim N\left(\operatorname{vec}\left(a_{0}(i)\right), V_{a}(i)\right) \\
\operatorname{vec}(\Phi(i)) \sim N\left(\operatorname{vec}\left(\Phi_{0}(i)\right), V_{\Phi_{0}}(i)\right) \\
\Omega(i) \sim I W\left(\Omega_{0}(i), v_{0}(i)\right)
\end{gathered}
$$

where $N$ denotes a normal and $I W$ an inverted Wishart distribution with known hyperparameters.

As for a transition probabilities $q_{i j}=\operatorname{Pr}\left(s_{t}=j \mid s_{t-1}=i\right), i, j=0, \ldots, m-1$, we assign a beta distribution as $q_{i j} \sim \operatorname{beta}\left(u_{i j}, \bar{u}_{i j}\right)$ where $u_{i j}$ and $\bar{u}_{i j}$ are defined as $u_{i j}=\operatorname{Pr}\left(s_{t} \neq i \mid s_{t-1}=i\right)$ and $\bar{u}_{i j}=\operatorname{Pr}\left(s_{t}=j \mid s_{t-1}=\right.$ $\left.i, s_{t} \neq i\right)$ for $i \neq j$ with density $\pi\left(q_{i j} \mid u_{i j}, \bar{u}_{i j}\right)=\frac{\Gamma\left(u_{i j}+\bar{u}_{i j}\right)}{\Gamma\left(u_{i j}\right)+\Gamma\left(\bar{u}_{i j}\right)} q_{i j}^{u_{i j}-1}\left(1-q_{i j}\right)^{\bar{u}_{i j}-1}$.

With these priors and the likelihood, we derive the conditional posterior distributions for these parameters (see Sugita (2016) for derivation for these posteriors). As for the conditional posterior for $b^{*}(i)$,

$$
\operatorname{vec}\left(b^{*}(i)\right) \mid a(i), \Phi(i), \Omega(i), q, \tilde{S}_{T}, Y \sim N\left(\operatorname{vec}\left(b_{1}^{*}(i), V_{b_{1}}(i)\right)\right.
$$

where

$$
\begin{aligned}
& V_{b_{1}}(i)=\left[V_{b_{0}}^{-1}(i)+\left(a(i) \Omega(i)^{-1} a(i)^{\prime} \otimes\left(Z(i)^{\prime} Z(i)\right]^{-1}\right.\right. \\
& \operatorname{vec}\left(b_{1}^{*}(i)\right)=V_{b_{1}}(i)\left[V_{b_{0}}^{-1}(i) \operatorname{vec}\left(b_{0}(i)\right)+\left\{\left(a(i) \Omega(i)^{-1}\right) \otimes Z(i)^{\prime}\right\} \operatorname{vec}(Y(i)-X(i) \Phi(i))\right] .
\end{aligned}
$$

As for the conditional posterior for $a(i)$,

where

$$
\operatorname{vec}(a(i)) \mid b^{*}(i), \Phi(i), \Omega(i), q, \tilde{S}_{T}, Y \sim N\left(\operatorname{vec}\left(a_{1}(i), V_{a_{1}}(i)\right)\right.
$$

$$
\begin{aligned}
& V_{a_{1}}(i)=\left[V_{a_{0}}^{-1}(i)+\Omega(i)^{-1} \otimes\left(b(i)^{\prime} Z(i)^{\prime} Z(i) b(i)\right)\right]^{-1} \\
& \operatorname{vec}\left(a_{1}(i)\right)=V_{a_{1}}(i)\left[V_{a_{0}}^{-1}(i) \operatorname{vec}\left(a_{0}(i)\right)+\left\{\Omega(i)^{-1} \otimes b(i)^{\prime} Z(i)^{\prime}\right\} \operatorname{vec}(Y(i)-X(i) \Phi(i))\right] .
\end{aligned}
$$

The conditional posterior for $\operatorname{vec}(\Phi(i))$ is obtained as:

$$
\operatorname{vec}(\Phi(i)) \mid a(i), b^{*}(i), q, \Phi(i), \Omega(i), \tilde{S}_{T}, Y \sim N\left(\operatorname{vec}\left(\Phi_{1}(i), V_{\Phi_{1}}(i)\right)\right.
$$

where

$$
V_{\Phi_{1}}(i)=\left[V_{\Phi_{0}}^{-1}(i)+\Omega(i)^{-1} \otimes\left(X^{\prime} X\right)\right]^{-1}
$$




$$
\operatorname{vec}\left(\Phi_{1}(i)\right)=V_{\Phi_{1}}(i)\left[V_{a_{0}}^{-1}(i) \operatorname{vec}\left(\Phi_{0}(i)\right)+\left\{\Omega(i)^{-1} \otimes X(i)^{\prime \prime}\right\} \operatorname{vec}\left(Y(i)-Z(i) b^{*}(i) a(i)\right)\right] .
$$

Regarding the conditional posterior for $\Omega(i)$, we obtain an inverted Wishart distribution as:

$$
\Omega(i) \mid a(i), b^{*}(i), q, \Phi(i), \tilde{S}_{T}, Y \sim I W\left(\left(Y_{i}-W_{i} B\right)^{\prime}\left(Y_{i}-W_{i} B\right)+\Omega_{0}(i), t_{i}+v_{0}(i)+n+1\right)
$$

To derive the state variable $\tilde{S}_{T}=\left\{s_{1}, \ldots, s_{T}\right\}^{\prime}$, we employ the multi-move Gibbs sample, which is originally proposed by Carter and Kohn (1994) and is applied to a Markov switching dynamic factor model by Kim and Nelson (1998), see Sugita (2016) for detail. To generate the transition probabilities $q_{i j}$, we follow Albert and Chib (1993) and Kim and Nelson (1998).

$$
p\left(q_{i j} \mid \bar{S}_{T}\right) \propto q_{i j}^{u_{i j}+m_{i j}-1}\left(1-\bar{q}_{i j}\right)^{\bar{u}_{i j}+\bar{m}_{i j}-1}
$$

where $m_{i j}, i, j=1, \ldots, m$, denotes the number of the transition from the regime $i$ to $j$, that can be counted for given $\tilde{S}_{T}$.

Given the conditional posterior distributions from (9) to (13), we implement the Gibbs sampling to generate sample draws.

\section{Empirical Results}

In this section, we examine Japanese Fisher effect using the MSVECM in (2). We employ quarterly data for Japan from 1960:1 to 2016:3 with 228 observations from the International Financial Statistics. The nominal interest rate is the money market rate, $R_{t}$. The inflation rate, $\pi_{t}$, is calculated from the first differences of the natural logarithm of the CPI, multiplied by 400 to obtain annualized rates in percent. Figure 1 plots the money market rate in the left and the inflation rate in the right. We first test for unit roots in the interest rate, $R_{t}$, and the inflation rate, $\pi_{t}$. We apply the ADF (Augmented Dickey-Fuller) test, ADF-GLS test by Elliot et al. (1996), and test by Kwiatkowski et al. (1992). The lag length is chosen based on the Akaike information criterion (AIC) for the ADF tests, and the modified Akaike information criterion (MAIC), that is proposed by Perron and Qu (2007), for the ADF-GLS and the KPSS tests. Both the ADF and the ADF-GLS tests the null hypothesis of a unit root, while the KPSS tests the null of stationary. Table 1 shows that we cannot reject the null of a unit root for the both variables and the KPSS test reject the null of stationary when only a constant is considered in the regression. However, when both constant and trend are considered, the results are somewhat ambiguous for the interest rate $R_{t}$, the ADF-GLS test rejects the null of a unit root with 5\% significant level while the KPSS test rejects the null of stationary.

Table 1. Tests for unit roots

\begin{tabular}{ccccccc}
\hline & ADF & ADF & ADF-GLS & ADF-GLS & KPSS & KPSS \\
Variable & $\tau_{c}$ & $\tau_{c t}$ & $\tau_{c}$ & $\tau_{c t}$ & cons & cons\&trend \\
\hline$R_{t}$ & -1.3222 & $-3.2526^{*}$ & -0.3420 & $-2.9813^{* *}$ & $2.0120^{* * *}$ & $0.1640^{* *}$ \\
$\pi_{t}$ & -1.7365 & -3.0120 & $-1.7332^{*}$ & -2.0529 & $1.2231^{* * *}$ & $0.1243^{*}$ \\
\hline
\end{tabular}

Note. $\tau_{c}$ is the test statistic for unit root with the drift term. $\tau_{c t}$ is with both drift and time trend terms.

\subsection{Linear VECM}

In this subsection, we proceed to apply a linear VECM in (1), where $y_{t}=\left(R_{t}, \pi_{t}\right)$. We compute the marginal likelihood by Chib (1995) for all models under consideration. We set the prior specification as $b=0$ and $V_{b 0}=5 I$ in (5), $a_{0}=0$ and $V_{a 0}=5 I$ in (6) $\Phi_{0}=0$ and $V_{\Phi 0}=5 I$ in (7), $v_{0}=10$ and $\Omega_{0}=I$ in (8). The full Gibbs sampler is run with 10,000 draws and additional $4 \times 10,000$ draws for the reduced Gibbs sampler to calculate the marginal likelihood by the Chib's method. We consider various models that contain or do not contain deterministic constant term and/or time trend in the cointegration relations and/or in the VECM, and conclude that no deterministic term in either cointegration relations or the VECM is needed. Table 2 gives the logarithms of marginal likelihoods for models with different cointegrating rank and different lag length and with no deterministic term added in the model. We vary the number of rank from $r=0$ to 2 and the lag length from $p=1$ to 5 . We also consider the case that the cointegrating vector is restricted with $\beta=(1,-1)$, denoting $r=1^{R}$, if the Fisher effect holds. We find that the model with the highest marginal likelihood has cointegrating rank $r=1$ and the lag length $p=2$, however, the Fisher effect $\left(r=1^{R}\right)$ does not seem to hold. We also compute the Bayes factor to test the Fisher effect using the Savage-Dickey density ratio, proposed by Verdinelli and Wasserman (1995). The Bayes factor by the Savage-Dickey density ratio, $B F_{S D D R}$, is defined as:

$$
B F_{S D D R}=\frac{p\left(b=b^{R} \mid Y\right)}{p\left(b=b^{R}\right)}
$$


where the denominator, the marginal prior for $b$ evaluated at $b=(1,-1)$, can be computed using (5). The numerator of (14) is the marginal posterior for $\beta$ evaluated at $b=(1,-1)$ and can be obtained by integrating out the other parameters, such as:

$$
\begin{aligned}
p\left(b=b^{R} \mid Y\right) & =\iiint p\left(b=b^{R} \mid a, \Phi, \Omega, Y\right) p(a, \Phi, \Omega \mid Y) \operatorname{dad} \Phi d \Omega \\
& \simeq \frac{1}{N} \sum_{i=1}^{N} p\left(b=b^{R} \mid a_{i}, \Phi_{i}, \Omega_{i}, Y\right)
\end{aligned}
$$

where the subscript $i$ denotes the sample from the posterior; $p\left(b=b^{R} \mid a_{i}, \Phi_{i}, \Omega_{i}, Y\right)$ is the conditional posterior density (9) evaluated at $b=b^{R}$. The computed $B F_{S D D R}$ by the Savage-Dickey density ratio (14) is 1.6924, which is "not worth more than a bare mention", according to the guidelines provided by Kass and Raftery (1995). Thus, from the marginal likelihood and the Bayes factor by the Savage-Dickey density ratio, we can conclude that the linear VECM find the one cointegrating relation but does not give strong support for the Fisher effect. Table 3 gives the results by the Johansen's trace test for cointegration for reference. We select the lag length $p=2$ by the Schwarz's BIC and $p=5$ by the Hannan-Quinn criterion, and the model without any deterministic terms in the VECM. The Johansen's classical tests also reject the null of no cointegration and cannot reject the null of $r=1$ at the 5\% significance level with either lag length.

Table 2. Linear VECM: Model selection by logarithm of marginal likelihoods

\begin{tabular}{cccccc}
\hline Rank & \multicolumn{5}{c}{ Lag length } \\
\cline { 2 - 5 } & $p=1$ & $p=2$ & $p=3$ & $p=4$ & $p=5$ \\
\hline$r=0$ & -911.51 & -842.79 & -845.30 & -835.85 & -841.73 \\
$r=1$ & -805.70 & $-\mathbf{7 8 7 . 9 3}$ & -798.60 & -791.87 & -823.07 \\
$r=2$ & -876.71 & -836.53 & -850.13 & -849.17 & -861.60 \\
$r=1^{R}$ & -868.06 & -832.70 & -844.14 & -838.64 & -850.43 \\
\hline
\end{tabular}

Table 3. Johansen's cointegration tests

\begin{tabular}{ccccc}
\hline$H_{0}$ & \multicolumn{2}{c}{ Trace test $(p=2)$} & \multicolumn{2}{c}{ Trace test $(p=5)$} \\
\hline Rank & statistic & $p$-val & statistic & $p$-val \\
\hline$r=0$ & 54.606 & 0.0000 & 19.357 & 0.0025 \\
$r=1$ & 3.6802 & 0.0655 & 2.7444 & 0.1139 \\
\hline
\end{tabular}

Note. We consider the VECM with no deterministic terms. The lag length $p=2$ is selected by the Schwarz's Bayesian information criterion, and $p=5$ by the Hannan-Quinn criterion.

\subsection{MSVECM}

In this subsection, we move on to the non-linear analysis using the MSVECM in (2). We consider the MSVECM with both two and three regimes to compute the marginal likelihood for model selection, and find that there is never any evidence for three regimes. Accordingly, we focus on the MSVECM with two regimes to analyze the Japanese Fisher effect. We consider models with the cointegration rank $r=0$ or 1 for each regime, that is, $(r(0), r(1))=(0,0),(0,1),(1,0)$ and $(1,1)$. For the implications of the Fisher effect, we also consider models with the restriction on $\beta=(1,-1)$ in one or both regimes.

As in the case of the linear VECM, we compute the marginal likelihood by Chib (1995) for all models we consider, running the Gibbs sampler with 10,000 draws and the additional $4 \times 10,000$ draws for the marginal likelihood calculation. We need to add the bias correction as $\ln M L^{*}=\ln M L+\ln 2$ where $\ln M L^{*}$ is the corrected marginal likelihood and $\ln 2$ is the bias correction, see Frühwirth-Schnatter (2004) for detail. We set the prior specification as $b(i)=0$ and $V_{b_{0}}(i)=5 I$ in $(5), a_{0}(i)=0$ and $V_{a_{0}}(i)=5 I$ in $(6) \Phi_{0}(i)=0$ and $V_{\Phi_{0}}(i)=5 I$ in (7), $v_{0}(i)=10$ and $\Omega_{0}(i)=I$ in (8).

Table 4 gives the logarithms of marginal likelihoods for models with different cointegrating rank and different lag length in the two regimes. We find that the model with the highest marginal likelihood has the lag length of two in the regime 0 and one in the regime $1,(p(0), p(1))=(2,1)$, and specifies that both regimes are cointegrated but the Fisher effect restriction only holds in the regime $0,(r(0), r(1))=\left(1^{R}, 1\right)$. The marginal likelihood of 
this model is $M L^{*}=-549.91$, while the second largest marginal likelihood is $M L^{*}=-553.46$ for the model with $(p(0), p(1))=(2,1)$ and $(r(0), r(1))=(1,1)$. Compared with the results for the linear VECM, we find that the marginal likelihood for the MSVECM with $(p(0), p(1))=(2,1)$ and $(r(0), r(1))=\left(1^{R}, 1\right)$ is much higher than those for any linear VECM shown in Table 2. Thus, we find that the MSVECM, that supports the Fisher effect in one regime, is much preferred to the linear VECM, that does not support the Fisher effect. In other words, we can conclude that the evidence strongly supports the nonlinearities in Fisher effect.

We compute the posterior probability, $\operatorname{Pr}\left(M_{j} \mid Y\right)$, that is probability for model $M_{j}$ among all other models, defined by $\operatorname{Pr}\left(M_{j} \mid Y\right)=\frac{B F_{j k}}{\sum_{m=1}^{N} B F_{m j}}$ where $N$ is the number of models under consideration and $B F_{j k}$ is the Bayes factor for model $M_{k}$ against model $M_{j}$ and defined as $B F_{j k}=\exp \left(M L_{k}^{*}-M L_{j}^{*}\right)$. The posterior probability for the model with the highest marginal likelihood is 0.9251 , while it is 0.0266 for the second highest marginal likelihood. Therefore, the model with the highest marginal likelihood is dominant over the rest of models, and thus we can consider the model as the best fitted. If the highest marginal likelihood (and thus the posterior probability) is not dominant among other models, we would consider BMA (Bayesian model averaging) to deal with model uncertainty.

Figure 2 presents the posterior expectation of the regime variable, $\operatorname{Pr}\left(s_{t}=1 \mid Y\right)$. The Fisher effect holds only in the regime $0\left(s_{t}=0\right)$, and seems to not hold when the interest rate dropped suddenly and had been stable between 1965 and 1966 due to the securities market slump, and between 1995 and late 1997 after the bubble economy burst. The Fisher effect did not hold in the regime when the BOJ adopted the ZIRP between 1999 and 2000, and when the BOJ adopted the ZIRP and the QE policy during 2001 and 2006 and since 2008.

The posterior means, standard deviations, and the 95\%HPDI (highest posterior density interval) of parameters for the model with $(p(0), p(1))=(2,1)$ and $(r(0), r(1))=\left(1^{R}, 1\right)$ are reported in Table 5 . We find that the variance of both the interest rate and the inflation rate in regime 0 is much lower than those in the regime 0 . This is because the regime 1 is mainly characterized by the ZIRP. In regime 1, where there is no support for the Fisher effect, the cointegrating vector is estimated as $\beta(1)=(0.4753,-0.8769)$, or $\beta(1)=(1,-1.845)$ if the first element is normalized. The posterior density for $\beta(1)$ is plotted in Figure 3. We compute the Bayes factor to test the restriction for the Fisher effect by the Savage-Dickey density ratio in (14), and obtain the results as $B F_{S D D R}$ $=0.5156$, which is "not worth more than a bare mention" by Kass and Raftery (1995). In regime 0 when the Fisher effect holds, the $\alpha(0)_{1}$, that is the coefficient for the interest rate, is significantly negative, and the $\alpha(0)_{2}$, that is the coefficient for the inflation rate, is significantly positive. The posterior density for $\alpha(0)$ is plotted in the left column of the Figure 4. Thus, in the period when the Fisher effect holds, the adjustment toward equilibrium occurs through both the interest rates and the inflation rate. However, in regime 1 when the Fisher effect does not hold, $\alpha(1)_{1}$ is not significantly different from zero while $\alpha(1)_{2}$ is significant with positive sign, meaning that the interest rates does not respond against the disequilibrium and only inflation rate moves to adjust for the equilibrium. The posterior density for $\alpha(1)$ is plotted in the right column of the Figure 4. In regime 1 when the ZIPR was adopted, the interest rate has set to almost zero and has not been allowed to move for the adjustment toward the equilibrium.

\section{Conclusion}

We examined the empirical evidence on the relationship between the interest rate and inflation in Japan. We find that the linear VECM detects the cointegration relation but does not support the Fisher effect due to neglected non-linearity caused by the ZIRP. We employed a two-regime MSVECM to analyze Japanese Fisher effect, and find that, although the cointegration relation is found in both regimes, the Fisher effect is supported only in one regime. In the regime when the ZIRP had been adopted, the interest rate did not react against the disequilibrium and thus the Fisher effect does not hold. Thus, the monetary policy such as the ZIRP influenced the relationship between the nominal interest rates and the inflation rates.

The MSVECM that we employ in this paper is versatile and allows for regime shifts not only in the determinant terms, the adjustment of speed terms, lag terms, and the variance-covariance matrix but also in the number of cointegrating rank, the cointegrating vectors, and the lag length. Using this model, we find that the non-linearity is found in the error correction as well as other parameters. In this paper, we choose Markov switching as a switching behavior. However, it is possible to choose alternative regime switching model such as smooth transition model to analyze non-linearity of the Fisher effect. 
Table 4. MSVECM: Model selection by logarithms of marginal likelhoods

\begin{tabular}{cccccccccc}
\hline Lag & \multicolumn{7}{c}{ Cointegration rank in each regime $(r(0), r(1))$} \\
$(p(0), p(1))$ & $(0,0)$ & $(1,1)$ & $\left(1^{\mathrm{R}}, 1\right)$ & $\left(1,1^{\mathrm{R}}\right)$ & $\left(1^{\mathrm{R}}, 1^{\mathrm{R}}\right)$ & $(1,0)$ & $\left(1^{\mathrm{R}}, 0\right)$ & $(0,1)$ & $\left(0,1^{\mathrm{R}}\right)$ \\
\hline$(1,1)$ & -616.51 & -568.58 & -566.54 & -582.83 & -579.22 & -592.31 & -588.79 & -590.98 & -604.79 \\
$(1,2)$ & -607.65 & -578.06 & -575.99 & -600.21 & -596.83 & -591.92 & -588.03 & -596.28 & -621.08 \\
$(1,3)$ & -620.97 & -601.46 & -598.64 & -614.41 & -610.54 & -608.50 & -603.66 & -613.73 & -626.03 \\
$(1,4)$ & -616.89 & -600.62 & -605.32 & -609.33 & -606.33 & -600.84 & -596.81 & -620.73 & -622.28 \\
$(2,1)$ & -581.64 & -553.46 & -549.91 & -562.75 & -558.87 & -578.49 & -574.90 & -555.10 & -562.97 \\
$(2,2)$ & -571.70 & -559.65 & -556.80 & -572.02 & -568.68 & -568.53 & -564.71 & -560.20 & -571.68 \\
$(2,3)$ & -586.70 & -583.96 & -579.58 & -587.18 & -583.05 & -584.25 & -580.72 & -578.97 & -586.71 \\
$(2,4)$ & -581.07 & -576.61 & -585.07 & -587.04 & -583.17 & -578.70 & -575.37 & -587.23 & -587.47 \\
$(3,1)$ & -589.26 & -566.75 & -565.15 & -570.95 & -567.36 & -591.71 & -587.79 & -563.28 & -567.04 \\
$(3,2)$ & -581.35 & -573.07 & -569.85 & -581.03 & -577.11 & -581.66 & -578.30 & -570.61 & -576.75 \\
$(3,3)$ & -594.04 & -591.81 & -588.13 & -597.95 & -594.63 & -596.22 & -592.49 & -591.86 & -594.46 \\
$(3,4)$ & -589.27 & -597.67 & -591.86 & -598.55 & -595.35 & -590.20 & -587.59 & -583.03 & -595.92 \\
$(4,1)$ & -578.16 & -559.23 & -561.29 & -564.66 & -564.06 & -584.80 & -583.94 & -553.04 & -557.88 \\
$(4,2)$ & -572.69 & -568.62 & -566.25 & -575.70 & -575.14 & -577.73 & -576.42 & -567.17 & -569.85 \\
$(4,3)$ & -584.12 & -587.21 & -590.69 & -591.94 & -591.41 & -590.20 & -588.96 & -580.95 & -586.27 \\
$(4,4)$ & -592.55 & -587.02 & -588.53 & -597.23 & -595.59 & -597.75 & -595.17 & -581.22 & -588.44 \\
\hline
\end{tabular}

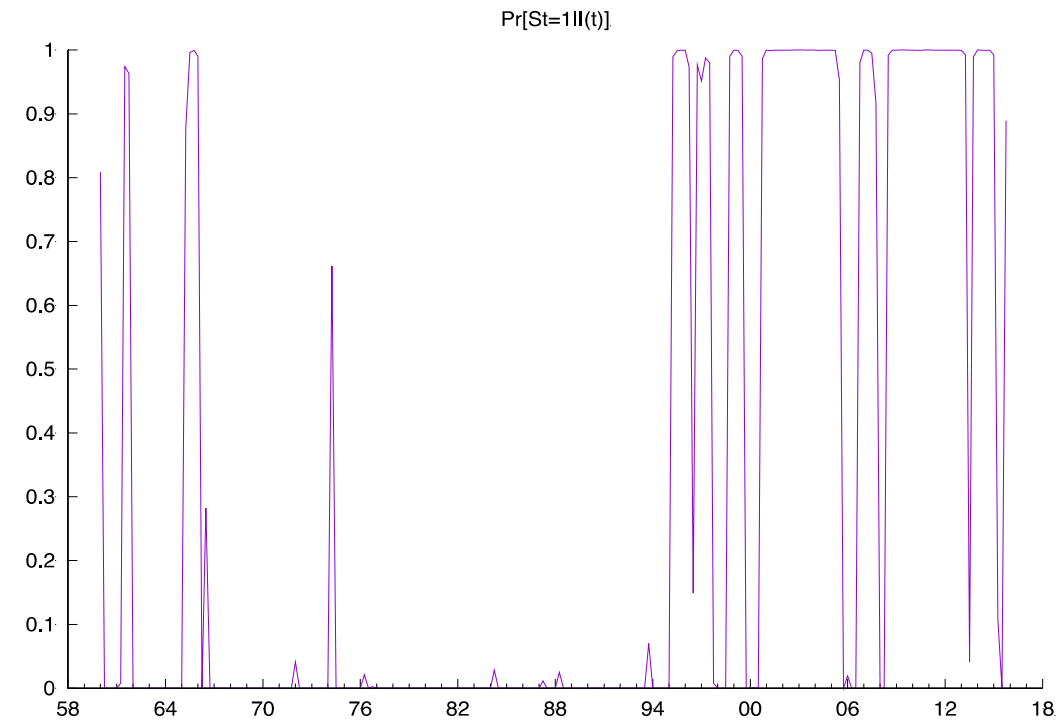

Figure 2. Posterior expectation of the regime variable

Table 5. Posterior parameter estimates

\begin{tabular}{|c|c|c|c|c|c|c|c|c|c|}
\hline \multirow[b]{2}{*}{$\beta(1)_{1}$} & \multirow{2}{*}{$\frac{\text { mean }}{0,4753}$} & \multirow{2}{*}{$\frac{\text { s.d. }}{0.0634}$} & \multicolumn{2}{|c|}{ 95\% HPDI } & \multicolumn{2}{|r|}{ mean } & \multirow{2}{*}{$\frac{\text { s.d. }}{0.0804}$} & \multicolumn{2}{|c|}{ 95\% HPDI } \\
\hline & & & 0.3388 & 0.5876 & $\Phi(0)_{2,2}^{1}$ & -0.3413 & & -04991 & -0.1829 \\
\hline$\beta(1)_{2}$ & -0.8769 & 0.0337 & -0.9409 & -0.8092 & $\Omega(0)_{1,1}$ & 0.3983 & 0.0457 & 0.3188 & 0.4975 \\
\hline$\alpha(0)_{1}$ & -0.0467 & 0.0197 & -0.0854 & -0.0077 & $\Omega(0)_{1,2}$ & 0.4268 & 0.0587 & 0.3261 & 0.5562 \\
\hline$\alpha(0)_{2}$ & 0.5940 & 0.1288 & 0.3389 & 0.8467 & $\Omega(0)_{2,2}$ & 17.029 & 1.8952 & 13.732 & 21.170 \\
\hline$\alpha(1)_{1}$ & 0.0000 & 0.0006 & -0.0013 & 0.0012 & $\Omega(1)_{1,1}$ & 0.0001 & 0.0000 & 0.0000 & 0.0002 \\
\hline$\alpha(1)_{2}$ & 1.1087 & 0.1136 & 0.8915 & 1.3373 & $\Omega(1)_{1,2}$ & 0.0000 & 0.0006 & -0.0019 & 0.0009 \\
\hline$\Phi(0)_{1,1}^{1}$ & 0.5025 & 0.0678 & 0.3690 & 0.6348 & $\Omega(1)_{2,2}$ & 2.4847 & 0.6332 & 1.6782 & 4.2487 \\
\hline$\Phi(0)_{1,2}^{1}$ & 1.1673 & 0.4394 & 0.3086 & 2.0310 & $q_{00}$ & 0.8675 & 0.0391 & 0.7823 & 0.9352 \\
\hline$\Phi(0)_{2,1}^{1}$ & -0.0053 & 0.0123 & -0.0292 & 0.0190 & $q_{11}$ & 0.9270 & 0.0214 & 0.8802 & 0.9633 \\
\hline
\end{tabular}

Note. $\Phi(i)_{j, k}^{p}$ denotes the $j$-th row and the $k$-th column element in the matrix $\Phi(i)_{j}^{p}$ that is $i$-th regime, $p$-th lag of the lag matrix. $\Omega(i)_{j, k}$ denotes the $j$-th row and the $k$-th column element in the matrix $\Omega(i)$. 

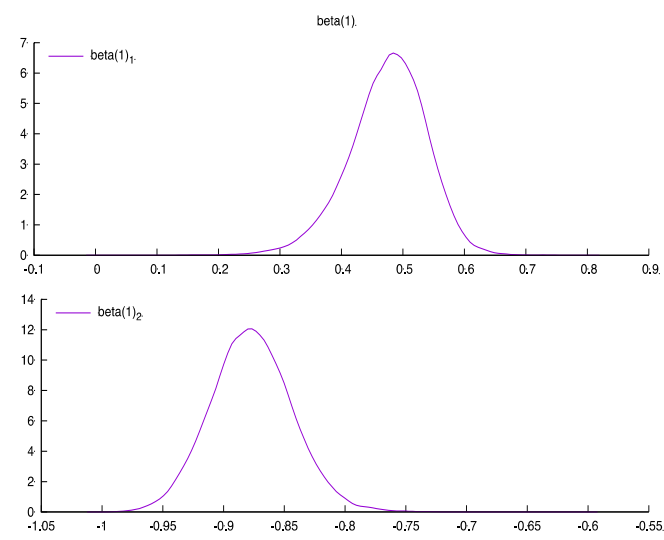

Figure 3. Posterior density for $\beta(1)$
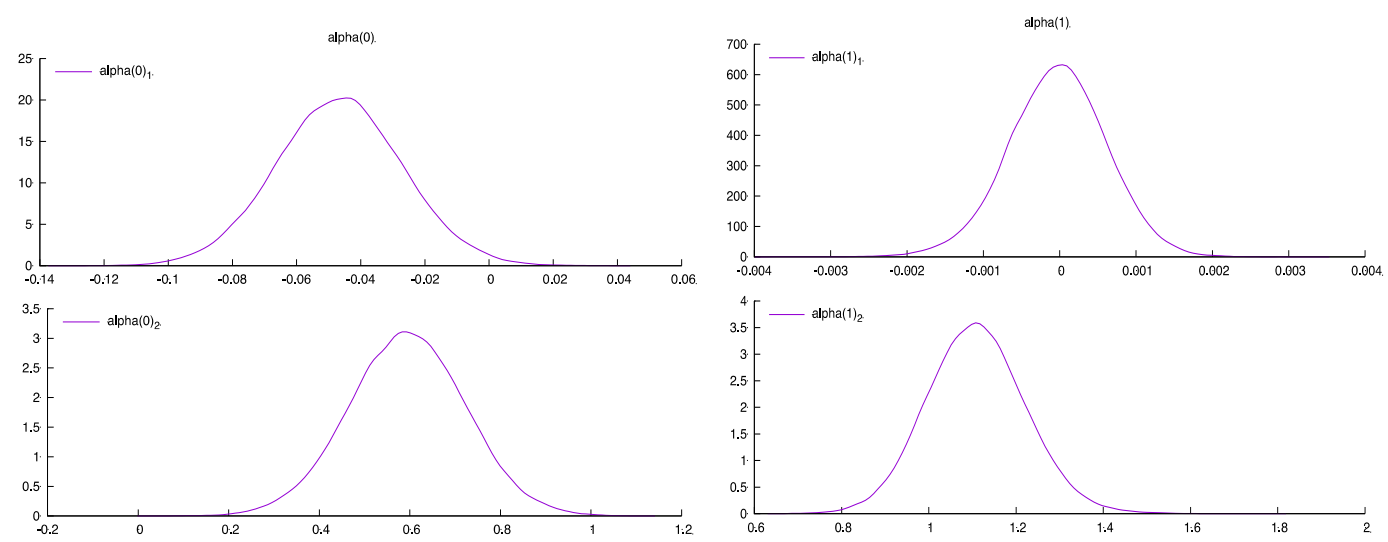

Figure 4. Posterior density for $\alpha(0)$ and $\alpha(1)$

\section{Acknowledgements}

This work was supported by JSPS KAKENHI Grant Number 17 K03661.

\section{References}

Albert, J. H., \& Chib, S. (1993). Bayes inference via Gibbs sampling of autoregressive time series subject to Markov mean and variance shifts. Journal of Business \& Economic Statistics, 11(1), 1-15. http://dx.doi.org/10.2307/1391303

Atkins, F. J., \& Serletis, A. (2003). Bounds Tests of the Gibson Paradox and the Fisher Effect: Evidence from Low-Frequency International Data. The Manchester School, 71(6), 673-679. http://dx.doi.org/10.1046/j.1467-9957.2003.00373.x

Beyer, A., Haug, A. A., \& Dewald, W. G. (2009). Structural breaks, cointegration and the Fisher effect. ECB Working Paper.

Bierens, H. J. (2000). Nonparametric nonlinear cotrending analysis, with an application to interest and inflation in the United States. Journal of Business \& Economic Statistics, 18(3), 323-337. http://dx.doi.org/10.1080/07350015.2000.10524874

Carter, C. K., \& Kohn, R. (1994). On Gibbs sampling for state space models. Biometrika, 81(3), $541-553$. http://dx.doi.org/10.1093/biomet/81.3.541

Cheung, Y. W., \& Lai, K. S. (1993). Finite-sample sizes of Johansen's likelihood ratio tests for cointegration. Oxford Bulletin of Economics and Statistics, 313-328. http://dx.doi.org/10.1111/j.1468-0084.1993.mp55003003.x

Chib, S. (1995). Marginal likelihood from the Gibbs output. Journal of the American Statistical Association, 90(432), 1313-1321. http://dx.doi.org/10.1080/01621459.1995.10476635

Christopoulos, D. K., \& León-Ledesma, M. A. (2007). A Long-Run Non-Linear Approach to the Fisher Effect. 
Journal of Money, Credit and Banking, 39(2-3), 543-559. http://dx.doi.org/10.1111/j.0022-2879.2007.00035.x

Doornik, J. (2013). Object-Oriented Matrix Programming using Ox. London: Timberlake Consultants Press.

Elliot, B., Rothenberg, T., \& Stock, J. (1996). Efficient tests of the unit root hypothesis. Econometrica, 64(8), 13-36.

Engsted, T. (1995). Does the long-term interest rate predict future inflation? A multi-country analysis. The Review of Economics and Statistics, 42-54. http://dx.doi.org/10.2307/2109991

Frühwirth-Schnatter, S. (2004). Estimating marginal likelihoods for mixture and Markov switching models using bridge sampling techniques. The Econometrics Journal, 7(1), 143-167.

Gregory, A. W., Nason, J. M., \& Watt, D. G. (1996). Testing for structural breaks in cointegrated relationships. Journal of Econometrics, 71(1), 321-341.

Jochmann, M., \& Koop, G. (2015). Regime-switching cointegration. Studies in Nonlinear Dynamics \& Econometrics, 19(1), 35-48. http://dx.doi.org/10.1515/snde-2012-0064

Kapetanios, G., Shin, Y., \& Snell, A. (2003). Testing for a unit root in the nonlinear STAR framework. Journal of Econometrics, 112(2), 359-379.http://dx.doi.org/10.1016/S0304-4076(02)00202-6

Kass, R. E., \& Raftery, A. E. (1995). Bayes factors. Journal of the American Statistical Association, 90(430), 773-795. http://dx.doi.org/10.1080/01621459.1995.10476572

Kim, C. J., \& Nelson, C. R. (1998). Business cycle turning points, a new coincident index, and tests of duration dependence based on a dynamic factor model with regime switching. Review of Economics and Statistics, 80(2), 188-201. http://dx.doi.org/10.1162/003465398557447

Koop, G., León-González, R., \& Strachan, R. W. (2010). Efficient posterior simulation for cointegrated models with priors on the cointegration space. Econometric Reviews, 29(2), 224-242. http://dx.doi.org/10.1080/07474930903382208

Kwiatkowski, D., Phillips, P. C., Schmidt, P., \& Shin, Y. (1992). Testing the null hypothesis of stationarity against the alternative of a unit root: How sure are we that economic time series have a unit root? Journal of Econometrics, 54(1-3), 159-178. http://dx.doi.org/10.1016/0304-4076(92)90104-Y

Lanne, M. (2006). Nonlinear dynamics of interest rate and inflation. Journal of Applied Econometrics, 21(8), 1157-1168. http://dx.doi.org/10.1002/jae.908

Perron, P., \& Qu, Z. (2007). A simple modification to improve the finite sample properties of $\mathrm{Ng}$ and Perron's unit root tests. Economics Letters, 94(1), 12-19.

Rapach, D. E. (2003). International evidence on the long-run impact of inflation. Journal of Money, Credit, and Banking, 35(1), 23-48. http://dx.doi.org/10.1353/mcb.2003.0005

Rapach, D. E., \& Weber, C. E. (2004). Are real interest rates really nonstationary? New evidence from tests with good size and power. Journal of Macroeconomics, 26(3), 409-430. http://dx.doi.org/10.1016/j.jmacro.2003.03.001

Sugita, K. (2016). Bayesian inference in Markov switching vector error correction model. Economics Bulletin, 36(3), 1534-1546.

Verdinelli, I., \& Wasserman, L. (1995). Computing Bayes factors using a generalization of the Savage-Dickey density ratio. Journal of the American Statistical Association, 90(430), 614-618. http://dx.doi.org/10.1080/01621459.1995.10476554

\section{Notes}

Note 1. The BOJ shifted its main operating target from the policy rate to the current account balance at the bank.

\section{Copyrights}

Copyright for this article is retained by the author(s), with first publication rights granted to the journal.

This is an open-access article distributed under the terms and conditions of the Creative Commons Attribution license (http://creativecommons.org/licenses/by/4.0/). 